\title{
Development of Intravascular Large B-cell Lymphoma during Methotrexate Treatment for Rheumatoid Arthritis
}

\author{
Tomohisa Tabuchi, Hirosaka Inoue and Kosuke Obama
}

\begin{abstract}
:
A 56-year-old woman with rheumatoid arthritis who had been taking methotrexate (MTX) for six years visited our hospital with dyspnea and dizziness. Abdominal ultrasonography revealed mild splenomegaly. Laboratory examinations showed a marked elevation in soluble interleukin-2 receptor and lactate dehydrogenase levels. These abnormalities revealed a spontaneous regression after MTX discontinuation, however, they worsened again four months later. Skin biopsies revealed a diagnosis of intravascular large B-cell lymphoma (IVLBCL), and we diagnosed MTX-associated IVLBCL (MTX-IVLBCL) based on its characteristic course. Despite the recurrence of IVLBCL, it showed a good response to chemotherapy. MTX-IVLBCL should therefore be treated with consideration since it has different characteristics from that of de novo IVLBCL.
\end{abstract}

Key words: rheumatoid arthritis, methotrexate, lymphoproliferative disorder, intravascular lymphoma, immunological surveillance

(Intern Med Advance Publication)

(DOI: 10.2169/internalmedicine.7531-21)

\section{Introduction}

Methotrexate (MTX) has been widely used in recent years as a key drug in the treatment of rheumatoid arthritis (RA). Patients with RA are known to be at a high risk for complications associated with lymphoproliferative disorder (LPD) (1). A case of spontaneous regression of LPD after MTX discontinuation was reported in 1993, and the involvement of MTX in the development of LPD was thus proposed (2). MTX-associated LPD (MTX-LPD) is now classified as one of the iatrogenic immunodeficiency-associated LPDs (OIIA-LPDs), in the current WHO classification revised fourth edition (3). Although the epidemiological background of the disease is still unclear, the incidence of lymphoma in patients with RA is significantly higher in Japan, and MTX has been shown to be a risk factor for the disease (4).

In this study, we report a case of intravascular large Bcell lymphoma (IVLBCL) development during MTX therapy for RA. Since it had a unique clinical course, it was considered to be MTX-LPD and the patient responded well to chemotherapeutic treatment. IVLBCL such as MTX-LPD is ex- tremely rare, and its clinical features are not well known. We herein report the details of the case and discuss the clinical features of MTX-associated IVLBCL (MTXIVLBCL) in light of previous reviews (5-9).

\section{Case Report}

A 56-year-old woman with RA, who had been treated with MTX for six years, visited our hospital complaining of dyspnea and dizziness. There was no fever, skin rash, or superficial lymphadenopathy. Initial laboratory examinations showed a red blood cell count of $360 \times 10^{6}$ cells $/ \mu \mathrm{L}$, hemoglobin concentration of $10.8 \mathrm{~g} / \mathrm{dL}$, lactate dehydrogenase (LDH) level of 1,314 U/L, and soluble interleukin-2 receptor (sIL-2R) level of 2,570 U/mL (normal range, 157-474 U/ $\mathrm{mL}$ ). Abdominal ultrasonography revealed mild splenomegaly. Her symptoms and laboratory findings normalized after the discontinuation of MTX, and her lymphocyte count was increased from 510 cells/ $\mu \mathrm{L}$ to 1,200 cells/ $\mu \mathrm{L}$. We diagnosed MTX-LPD based on the clinical course.

Four months later, at three months after the start of treatment with iguratimod (IGU), her lymphocyte count decreased to 630 cells $/ \mu \mathrm{L}$, and serum levels of LDH and sIL-2 

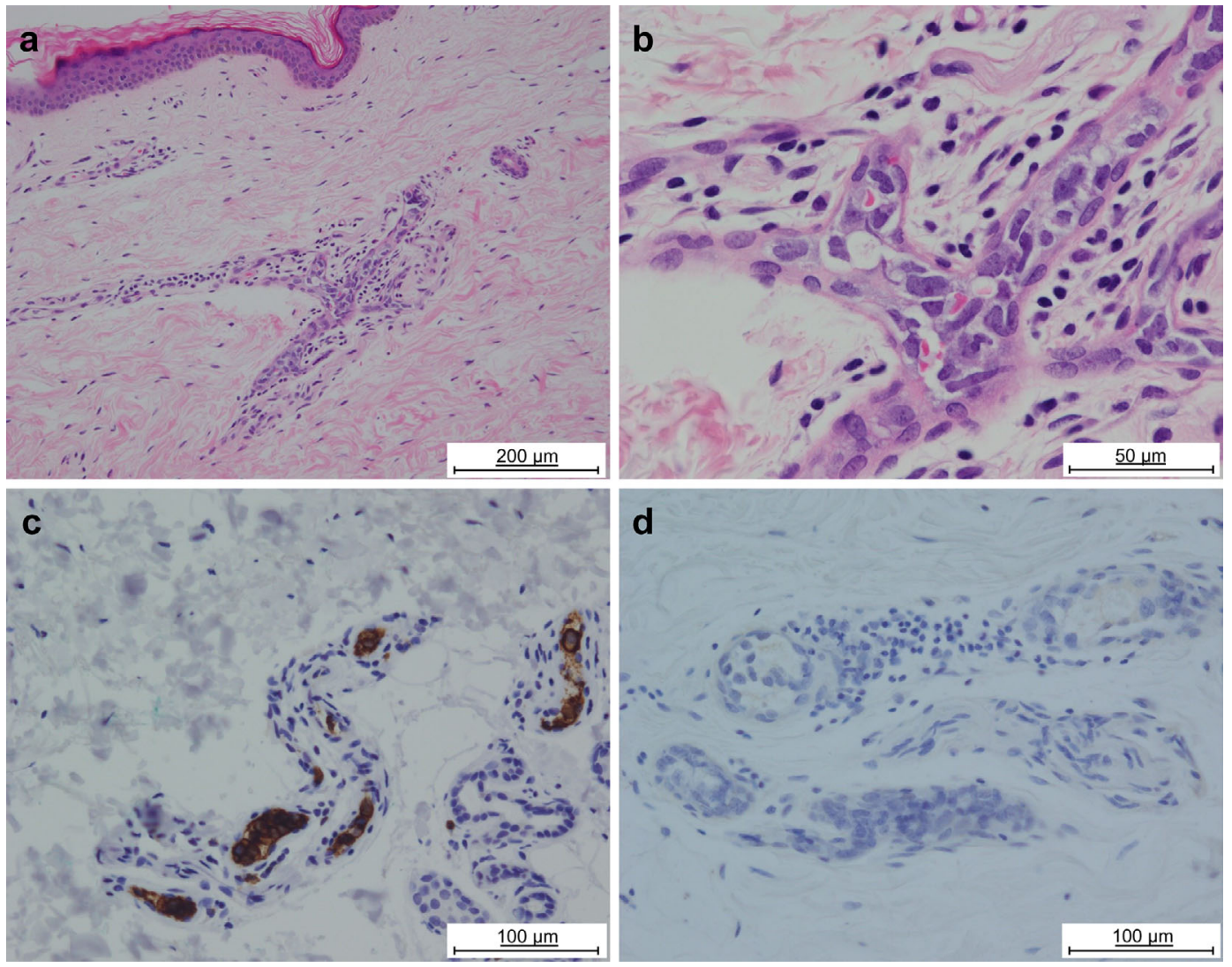

Figure 1. Pathological findings of a skin biopsy. (a, b) Large atypical lymphoid cells had proliferated in the small vessels. Immunohistochemical staining showed the cells to be positive for CD20 (c) and negative for Epstein-Barr virus encoded small RNA in situ hybridization (d).

$\mathrm{R}$ were elevated to $953 \mathrm{U} / \mathrm{L}$ and $1,720 \mathrm{U} / \mathrm{mL}$, respectively. However, no fever, dyspnea, skin rash, or superficial lymphadenopathy were observed. Laboratory test showed no pancytopenia. Computed tomography (CT) showed mesenteric lymphadenopathy and splenomegaly, and positron emission tomography (PET) scan showed an increased accumulation in the mesenteric lymph nodes and a diffuse accumulation in both lungs. Bone marrow aspiration revealed no malignancy or hemophagocytosis. Skin specimens randomly collected from the upper arm, abdomen, and thigh revealed large atypical lymphoid cell proliferation within the vessel. The atypical lymphoid cells were positive for CD20, CD79a, CD5, Ki-67, Bcl-6, and MUM1, but negative for CD3, CD 10, and Epstein-Barr virus encoded small RNA (EBER) in situ hybridization (Fig. 1). The serum Epstein-Barr virus deoxyribonucleic acid (EBV-DNA) quantitative test was under detection sensitivity. Mesenteric lymph node involvement is atypical, but based on these findings, the patient was diagnosed with IVLBCL. Magnetic resonance imaging of the head showed no abnormal signals, and cerebrospinal fluid cytology showed no atypical lymphoid cells.

Although we stopped IGU, her lymphocyte count did not recover, and the elevation in LDH and sIL-2R levels progressed. She received a total of six courses of rituximab, cyclophosphamide, doxorubicin, vincristine, and prednisolone (R-CHOP) therapy, two courses of rituximab and high-dose
MTX (R-HDMTX) therapy, four rounds of intrathecal MTX, cytarabine, and prednisolone infusions. Her laboratory findings thereafter normalized, and mesenteric lymphadenopathy and both lung diffuse accumulation had disappeared (Fig. 2). She has now been in complete remission (CR) for over 12 months since the onset of MTX-LPD.

\section{Discussion}

This is a case of IVLBCL that spontaneously regressed after MTX withdrawal, but later relapsed during treatment with disease-modifying anti-rheumatic drugs, and responded well to chemotherapy. Based on the characteristic course of the disease, it was assumed that it had a pathogenesis of MTX-LPD.

Although a tissue biopsy could not be performed because the patient did not have superficial lymphadenopathy at the initial diagnosis and the disease resolved quickly after MTX withdrawal, a clinical diagnosis of MTX-LPD was made based on the course of the disease. A CT scan at the time of recurrence showed mesenteric lymphadenopathy, but no other lymphadenopathy, and since the patient had mild splenomegaly, a random skin biopsy was performed at an early stage considering the possibility of IVLBCL, and specimens revealed large atypical B-lymphoid cell proliferation within the vessel. CT showed no abnormal findings in 


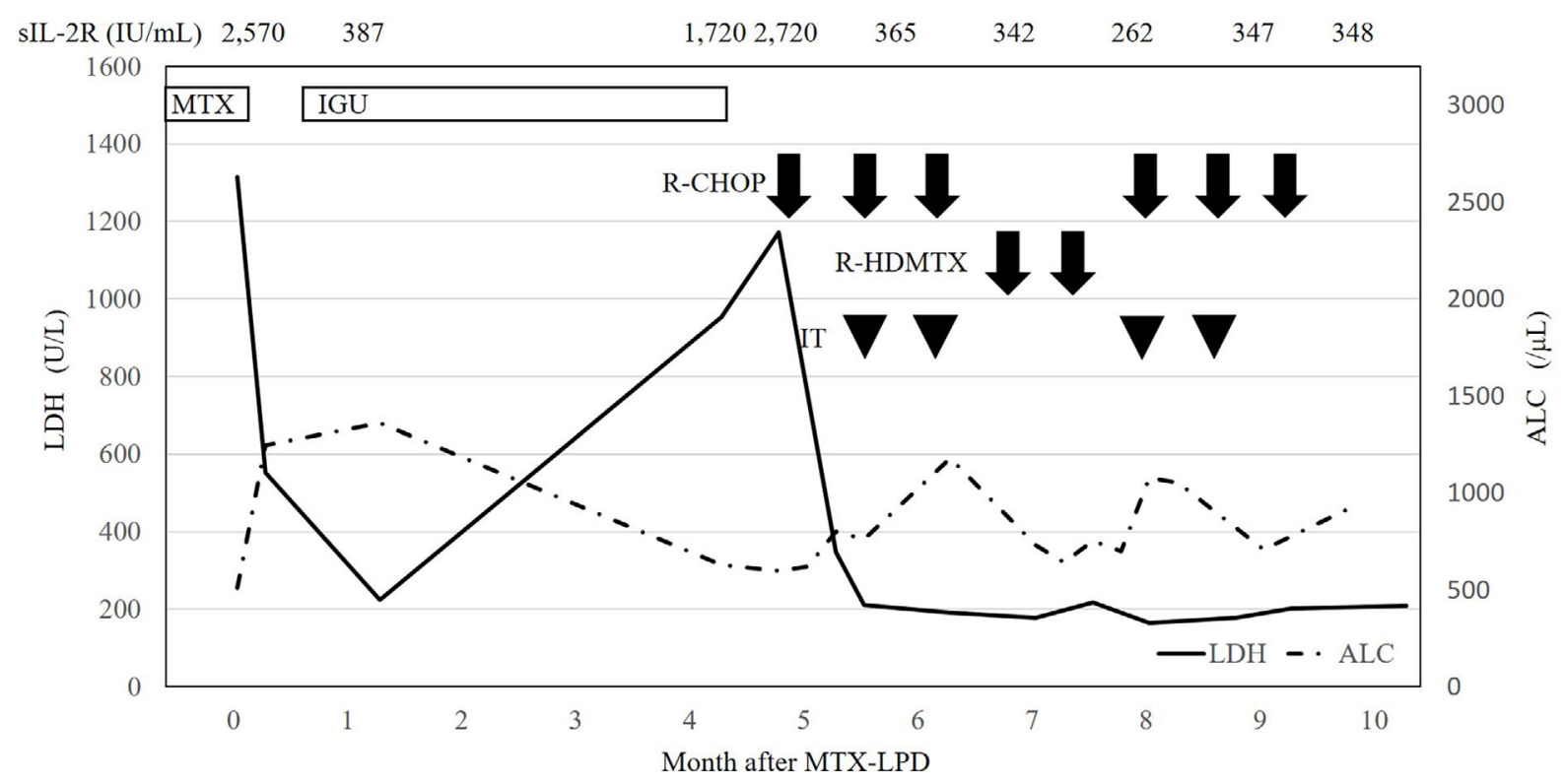

Figure 2. Clinical course of the patient. ALC: absolute lymphocyte count, IGU: iguratimod, IT: intrathecal methotrexate, cytarabine, and dexamethasone, LDH: lactate dehydrogenase, R-CHOP: rituximab, doxorubicin, cyclophosphamide, vincristine, and predonisolone, R-HDMTX: rituximab, high-dose methotrexate, sIL-2R: soluble interleukin-2 receptor

Table. MTX-associated IVLBCL in Literature.

\begin{tabular}{|c|c|c|c|c|c|c|c|c|c|c|c|}
\hline $\begin{array}{l}\text { Case } \\
\text { No. }\end{array}$ & $\begin{array}{l}\text { Age/ } \\
\text { Sex }\end{array}$ & Symptoms & $\begin{array}{c}\text { CNS } \\
\text { infiltration }\end{array}$ & $\begin{array}{c}\mathrm{BM} \\
\text { infiltration }\end{array}$ & HPS & $\begin{array}{c}\text { EBV } \\
\text { infection }\end{array}$ & $\begin{array}{c}\text { MTX } \\
\text { duration }\end{array}$ & $\begin{array}{l}\text { MTX stop } \\
\text { response }\end{array}$ & Chemotherapy & $\begin{array}{l}\text { Chemo } \\
\text { response }\end{array}$ & Ref \\
\hline 1 & $50 / \mathrm{F}$ & $\begin{array}{c}\text { Fever Leg } \\
\text { pain }\end{array}$ & $(+)$ & $(+)$ & $(-)$ & $(-)$ & $3 \mathrm{Y}$ & Regression & $\begin{array}{l}\text { R-CHOP } \\
\text { IT }\end{array}$ & $\mathrm{CR}$ & [5] \\
\hline 2 & $70 / \mathrm{F}$ & $\begin{array}{c}\text { Fever } \\
\text { Dyspnea }\end{array}$ & $(-)$ & $(-)$ & $(-)$ & $(-)$ & $7 \mathrm{Y}$ & Regression & & & [6] \\
\hline 3 & $76 / \mathrm{M}$ & $\begin{array}{c}\text { Fever } \\
\text { Dyspnea }\end{array}$ & $(-)$ & $(-)$ & $(-)$ & $(-)$ & $10 \mathrm{Y}$ & $\begin{array}{l}\text { Regression } \\
\rightarrow \text { Relapse }\end{array}$ & $\begin{array}{c}\text { R-THP-COP } \\
\text { IT } \\
\text { HDMTX }\end{array}$ & $\mathrm{CR}$ & [7] \\
\hline 4 & $56 / \mathrm{F}$ & $\begin{array}{l}\text { Dyspnea } \\
\text { Dizziness }\end{array}$ & $(-)$ & $(-)$ & $(-)$ & $(-)$ & $6 \mathrm{Y}$ & $\begin{array}{c}\text { Regression } \\
\rightarrow \text { Relapse }\end{array}$ & $\begin{array}{c}\text { R-CHOP } \\
\text { R-HDMTX } \\
\text { IT }\end{array}$ & $\mathrm{CR}$ & $\begin{array}{l}\text { This } \\
\text { case }\end{array}$ \\
\hline 5 & $75 / \mathrm{F}$ & $\begin{array}{l}\text { Fever } \\
\text { Malaise }\end{array}$ & $(+)$ & $(+)$ & $(-)$ & $(-)$ & $2 \mathrm{M}$ & Persistent & $\begin{array}{c}\text { R-hyperCVAD/ } \\
\text { MA }\end{array}$ & $\mathrm{CR}$ & [8] \\
\hline 6 & $59 / \mathrm{M}$ & $\begin{array}{c}\text { Fever } \\
\text { Dyspnea } \\
\text { Skin rash }\end{array}$ & $(+)$ & $(+)$ & $(+)$ & $(+)$ & $13 \mathrm{Y}$ & Persistent & R-CHOP & PD & [9] \\
\hline
\end{tabular}

CNS: central nervous system, BM: bone marrow, HPS: hemophagocytic syndrome, EBV: Epstein-Barr Virus, MTX: methotrexate, R-CHOP: rituximab, doxorubicin, cyclophosphamide, vincristine, and prednisolone, IT: intrathecal injection of anticancer drugs, CVAD/MA: cyclophosphamide, vincristine, doxorubicin, and dexamethasone/methotrexate and cytarabine, HDMTX: high-dose methotrexate, CR: complete remission, PD: progression disease, IVLBCL: intravascular large B-cell lymphoma

both lungs, but a PET scan showed a diffuse accumulation in both lungs, a finding suggestive of IVLBCL (10). Although the presence of lymphadenopathy is atypical, there are reports of lymphadenopathy in about $10 \%$ of IVLBCL (11), and we therefore finally diagnosed IVLBCL.

LPDs occurring in patients treated with immunosuppressive drugs are defined as OIIA-LPDs in the WHO classification revised fourth edition (3). Among these, the LPD that occurs in patients with RA treated with MTX is referred to as MTX-LPD. Since the report of MTX-associated IVLBCL in 2015, six cases, including this case, have been re- ported (5-9); their clinical characteristics are summarized in Table 1. Of these six cases, spontaneous regression with MTX cessation was observed in four cases, which was strongly suggestive of an MTX association. A relapse after MTX discontinuation was observed in three of four cases (case 2 relapsed 14 months after MTX discontinuation). These three patients responded well to chemotherapeutic treatment despite the recurrence of IVLBCL.

All reports of MTX-IVLBCL were from Japan, suggesting an association with the patient's ethnic background. IVLBCL is generally known to have a wide variety of clini- 
cal manifestations. The Asian variant, which is more common in East Asia, including Japan, is characterized by frequent bone marrow infiltration and hemophagocytic syndrome (HPS) (12). In these six cases, bone marrow involvement was found in three cases, but only one of them showed HPS. This case of HPS was associated with EBV and had a poor outcome. Although immunosuppressive drugs such as MTX may modify the clinical features, it is assumed that the pathogenesis may be essentially different from that of de novo IVLBCL. (In terms of overall survival, five of six patients, including two patients with central nervous system involvement, are still alive and in complete remission.) This favorable outcome therefore suggests that MTX-IVLBCL is a different concept from de novo IVLBCL.

In this case, lymphocyte recovery was observed after a spontaneous regression of MTX-LPD, and lymphocytopenia was observed again after a relapse of MTX-LPD. The spontaneous regression of MTX-LPD has been reported to be associated with lymphocyte recovery $(13,14)$, and this case also suggested an association between lymphocyte suppression and LPD. MTX inhibits cell proliferation and differentiation by inhibiting nucleic acid synthesis, and directly or indirectly regulates inflammatory cell functions through a number of mechanisms, including the induction of adenosine production (15). However, it is unlikely to induce a mutation in lymphocytes (16). Considering the unique clinical course of MTX-LPD, MTX may play a role in the development of LPD through a decrease in cell-mediated immunity associated with suppression of lymphocyte function. Four cases with a spontaneous regression were negative for EBV infection. It has been reported that the spontaneous regression of MTX-LPD correlates with the recovery of Th1 cells and effector memory $\mathrm{CD}^{+} \mathrm{T}$ cells regardless of EBV infection; an immune response to unknown LPD-related antigens was thought to be involved in MTX-LPD (17). IVLBCL with such a background of impaired immunological surveillance may not have a well-developed mechanism of tumorigenesis compared to de novo IVLBCL, which may be associated with both a spontaneous regression and favorable outcomes.

If the development of IVLBCL is suspected during MTX administration for RA, then an early diagnosis and early discontinuation of MTX and follow-up of lymphocyte counts are required. MTX-IVLBCL may often relapse after a spontaneous regression, but there may be a good response to chemotherapeutic treatment. MTX-IVLBCL is likely to be a disease with different characteristics from de novo IVLBCL, and the treatment strategies need to take this unique background into account.

The authors state that they have no Conflict of Interest (COI).

\section{References}

1. Hashimoto A, Chiba N, Tsuno H, et al. Incidence of malignancy and the risk of lymphoma in Japanese patients with rheumatoid arthritis compared to the general population. J Rheumatol 42: 564571, 2015.

2. Kamel OW, Van de RM, Weiss LM, et al. Brief report: reversible lymphomas associated with Epstein-Barr virus occurring during methotrexate therapy for rheumatoid arthritis and dermatomyositis. N Engl J Med 328: 1317-1321, 1993.

3. Gaulard P, Swerdlow SH, Harris NL, Sundstrom C, Jaffe ES. Other iatrogenic immunodeficiency-associated lymphoproliferative disorders. In: WHO classification of tumours of haematopoietic and lymphoid tissues. revised 4th ed. Swerdlow SH, Campo E, Harris NL, et al., Eds. IARC Press, Lyon, 2017: 462-464.

4. Honda S, Sakai R, Inoue E, et al. Association of methotrexate use and lymphoproliferative disorder in patients with rheumatoid arthritis: results from a Japanese multi-institutional retrospective study. Mod Rheumatol 11: 1-20, 2021.

5. Kikuchi J, Kaneko Y, Kasahara H, et al. Methotrexate-associated intravascular large B-cell lymphoma in a patient with rheumatoid arthritis. Intern Med 55: 1661-1665, 2016.

6. Iwami E, Ito F, Sasahara K, et al. Pulmonary intravascular large B-cell lymphoma in a patient administered methotrexate for rheumatoid arthritis. Intern Med 59: 429-433, 2020.

7. Hagihara $\mathrm{M}$, Mese $\mathrm{T}$, Ohara $\mathrm{S}$, Hua $\mathrm{J}$, Ide $\mathrm{S}$, Inoue $\mathrm{M}$. Methotrexate-associated intravascular large B-cell lymphoma in a patient with rheumatoid arthritis: a very rare case. Intern Med 57: 3001-3005, 2018.

8. Kida T, Kohno M, Chinen Y, et al. Intravascular lymphoma in a rheumatoid arthritis patient following short-term methotrexate treatment. Rheumatology (Oxford) 56: 318-320, 2017.

9. Komeno Y, Akiyama M, Okochi Y, et al. Hemophagocytic syndrome-associated intravascular large B-cell lymphoma in a rheumatoid arthritis patient. Case Rep Hematol 8947616, 2019.

10. Colavolpe C, Ebbo M, Trousse D, et al. FDG-PET/CT is a pivotal imaging modality to diagnose rare intravascular large B-cell lymphoma: case report and review of literature. Hematol Oncol 33: 99-109, 2015.

11. Murase T, Yamaguchi M, Suzuki R, et al. Intravascular large Bcell lymphoma (IVLBCL): a clinicopathologic study of 96 cases with special reference to the immunophenotypic heterogeneity of CD5. Blood 109: 478-485, 2007.

12. Murase $T$, Nakamura $S$, Kawauchi $K$, et al. An Asian variant of intravascular large B-cell lymphoma: clinical, pathological and cytogenetic approaches to diffuse large B-cell lymphoma associated with haemophagocytic syndrome. Br J Haematol 111: 826-834, 2000.

13. Inui $Y$, Matsuoka H, Yakushijin $\mathrm{K}$, et al. Methotrexate-associated lymphoproliferative disorders: management by watchful waiting and observation of early lymphocyte recovery after methotrexate withdrawal. Leuk Lymphoma 56: 3045-3051, 2015.

14. Saito S, Kaneko Y, Yamaoka K, Tokuhira M, Takeuchi T. Distinct patterns of lymphocyte count transition in lymphoproliferative disorders in patients with rheumatoid arthritis treated with methotrexate. Rheumatology (Oxford) 56: 940-946, 2017.

15. Bruce NC, Thomas MA. Methotrexate and its mechanisms of action in inflammatory arthritis. Nat Rev Rheumatol 16: 145-154, 2020.

16. Bleyer WA. Methotrexate induced lymphoma? J Rheumatol 25 : 404-407, 1998.

17. Saito S, Suzuki K, Yoshimoto K, et al. Restoration of decreased $T$ helper 1 and $\mathrm{CD} 8+\mathrm{T}$ cell subsets is associated with regression of lymphoproliferative disorders developed during methotrexate treatment. Front Immunol 9: 621, 2018.

The Internal Medicine is an Open Access journal distributed under the Creative Commons Attribution-NonCommercial-NoDerivatives 4.0 International License. To view the details of this license, please visit (https://creativecommons.org/licenses/ by-nc-nd/4.0/). 
(C) The Japanese Society of Internal Medicine Intern Med Advance Publication 